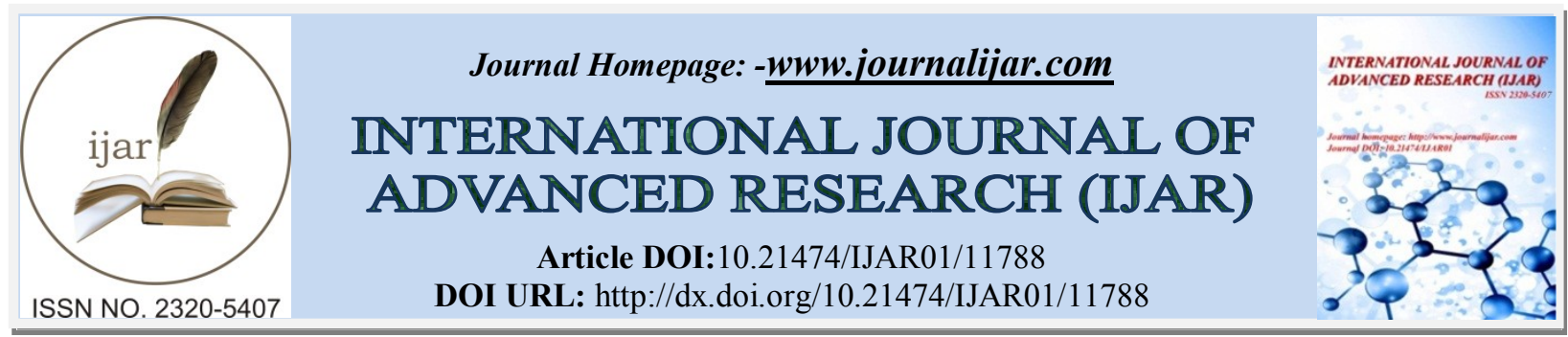

RESEARCH ARTICLE

\title{
DEGRADATION OF CONGO RED DYE USINGHYDRODYNAMIC CAVITATION
}

\author{
Dr. Satyajeet M. Deshmukh, Mrs. Vrushali N. Raut and Prashant M. Ingole
}

Assistant.Professor, Department of Chemical Engineering, Datta Meghe College of Engineering Airoli Navi Mumbai (India).

\section{Manuscript Info}

\section{Manuscript History}

Received: 25 July 2020

Final Accepted: 28 August 2020

Published: September 2020

Key words:-

Hydrodynamic Cavitation, Orifice,

Venturi, Congo Red Dye

\section{Abstract}

Hydrodynamic cavitation (HC) has been applied in the present work for the degradation of Congo red dye. Initially, the Effect of dilution of the Dye on the efficiency of hydrodynamic cavitation has been studied using circular orifice as well as venturi as a cavitator. The process parameters such as initial dye concentration, solution $\mathrm{pH}$, Hydraulic characteristics, comparative study of venturimeter and orificemeter, and flow rate were investigated in detail to evaluate their effects on the decolorization efficiency of Congo red Dye. In terms of removal rate and energy efficiency, an optimal inlet pressure value was found close to $0.4 \mathrm{MPa}$ and cavitation number of 0.25 . Maximum decolorization was obtained using orifice is $64 \%$, and that of venturi is $73 \%$ in $90 \mathrm{~min}$ time at a temperature of $25 \pm 2{ }^{\circ} \mathrm{C}$.

Copy Right, IJAR, 2020,. All rights reserved.

\section{Introduction:-}

\section{Overview:}

For decades, water pollution has attracted growing public attention as new toxic, refractory, and chemically stable compounds have been detected in the effluents of wastewater treatment plants (WWTP) all over the world [1]. Synthetic dyes are present in all spheres of our everyday life, and their application is consistently growing. The dye pollutants from the textile industry are the most important of environmental pollution; these effluents are toxic and mostly non-biodegradable. The trades involving production and application of dyes in the wastewater causes the primary threat to the surrounding ecosystems due to health hazard caused by toxicity. Wastewater from the textile industry containing dyes causes a severe environmental problem due to their intense color and potential toxicity. In recent years, effluents from the textile processing industry have become a cause of serious environmental concern. The use of synthetic chemical dyes by the textile industries in the various textile processing operations such as dyeing, printing, bleaching, and finishing operations has resulted in the release of large amounts of dye-containing industrial wastewater. [2] Textile wastewaters are found to have a large quantity of suspended particles, varied pH, dark-colored, with high chemical oxygen demand (COD), and high total organic carbon (TOC) [3] The presence of highly suspended solid particles with their intense color provides high turbidity in the textile effluents. Even a deficient concentration of these dyes (less than $1 \mathrm{ppm}$ for some dyes) induce color in water that is highly observable and undesirable and adversely affects the water bodies such as rivers, lakes, etc. [4]. Most of the dyes are toxic, and bio-recalcitrant in nature, and therefore conventional biological processes are found to be inefficient for the treatment of textile effluents[5]. The untreated textile wastewaters due to the presence of carcinogenic compounds are, therefore, very hazardous and toxic to human beings and animals also. Because the aquatic environment is damaged by the wastewaters discharged from textile dyeing industries, it is required to develop an eco-friendly and energy-efficient technique to treat the textile effluent before its discharge into the aquatic environment. Several 
conventional strategies comprised of various combinations of physical, chemical, and biological oxidation processes were developed for the treatment of textile effluents in the last decade.[6]

In recent years, cavitation as an advanced oxidation process (AOP) has been receiving more considerable attention for the treatment of wastewater [7][8]. Cavitation comprises of the nucleation, growth, and subsequent collapse of micro-bubbles or cavities, occurring in a small time interval at multiple locations in the reactor and thus releases a large magnitude of energy [9]. The collapse of cavities creates the 'hot spots' (very high temperature and pressure region) resulting in the formation of $\bullet \mathrm{OH}, \cdot \mathrm{H}, \mathrm{HO} 2 \cdot$, and cavitation can be produced by pressure variation in a flowing liquid through cavitating devices such as venturi or orifice plates, etc. When, the liquid passes through the geometries, the kinetic energy/velocity of the fluid increases at the expense of the pressure. The pressure at the throat or vena-contracta of the geometry drops below or equals the vapor pressure of the liquid due to sufficient throttling, and the liquid gets vaporized, thus creating several vaporous cavities. These cavities are further collapsed when pressure recovers downstream of the geometry. The collapse of cavities creates hot spots with extremely high temperatures up to $5,000 \mathrm{~K}$ and pressure up to $1000 \mathrm{~atm}[10]$

\section{Materials and methods:-}

\section{Materials:}

Congo Red Dye is an organic azo dye. Its chemical formula is $\mathrm{C}_{32} \mathrm{H}_{22} \mathrm{~N}_{6} \mathrm{Na}_{2} \mathrm{O}_{6} \mathrm{~S}_{2}$. with its molecular weight, 697 was purchased from S D Fine chemical ltd. Mumbai. Double distilled water (prepared freshly in the laboratory via distillation unit) was used to prepare the solution of congo red dye. Solution $\mathrm{pH}$ was adjusted using $\mathrm{NaOH}$ and $\mathrm{H}_{2} \mathrm{SO}_{4}$. All chemicals, as received from suppliers, were used for the experiments without any further purification.

\section{Experimental setup:}

Hydrodynamic cavitation reactor setup used in the present work is shown in Fig. 1. HC reactor setup consists: (1) a storage tank with $15 \mathrm{~L}$ capacity, (2) a high-pressure centrifugal pump is driven by a motor (power rating $1 \mathrm{~kW}$ ) (3) flow control valves (V1-V4), and pressure gauges (P1, P2), (4) a flow meter, (5) cavitating device venture and orifice accommodated with flanges. Pipes used in $\mathrm{HC}$ reactor have an internal diameter of $25 \mathrm{~mm}$. The suction side of a pump is connected to the bottom of a storage tank. The discharge from the pump branches into mainline and bypass line. The mainline consists of a cavitating device, and the flow rate of water in the mainline was controlled by regulating valve Pressure gauges (P1 and P2) are provided in main line to check the fluid pressure. The details of the cavitating devices used in the present work are given

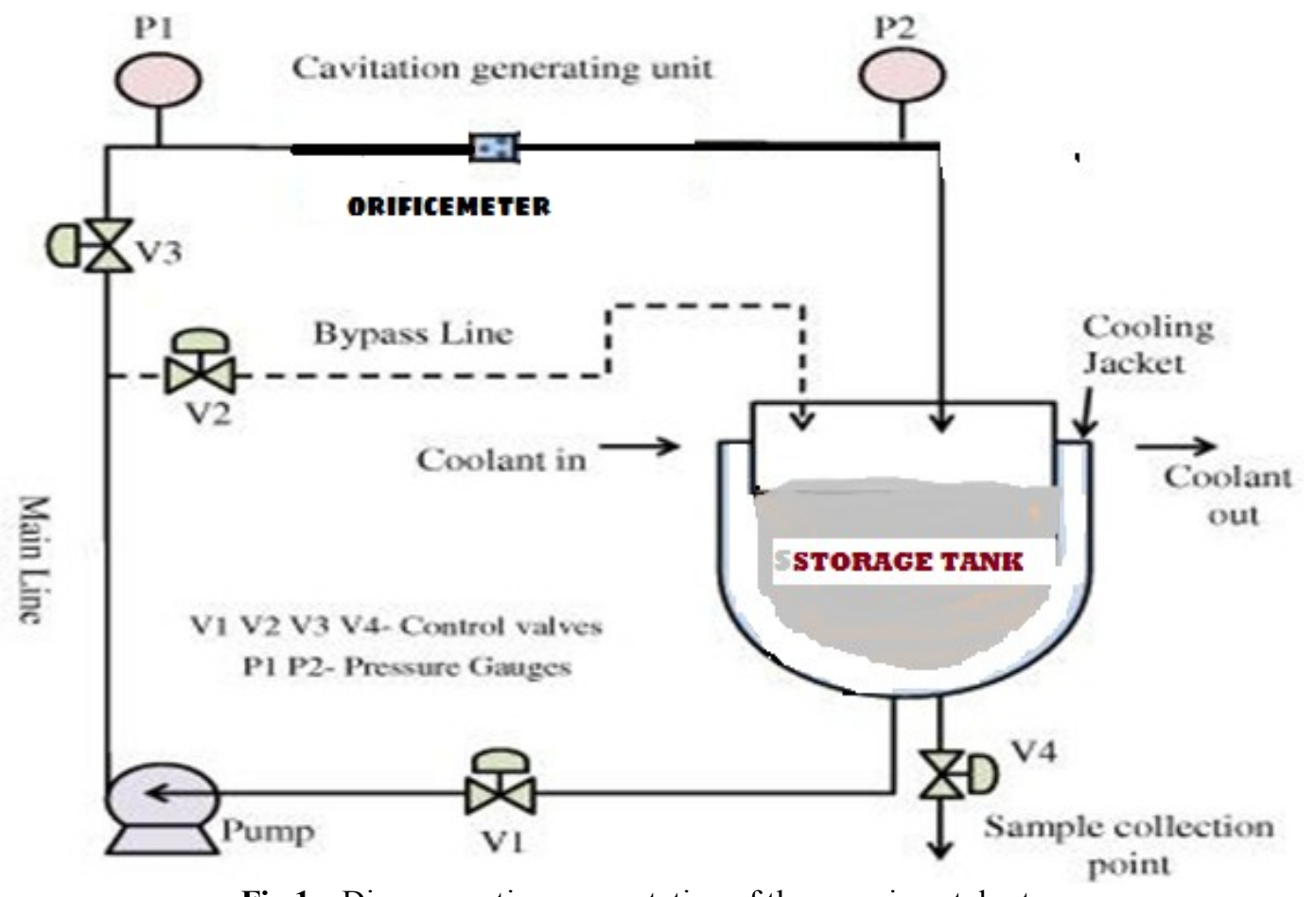

Fig 1:- Diagrammatic representation of the experimental setup. 


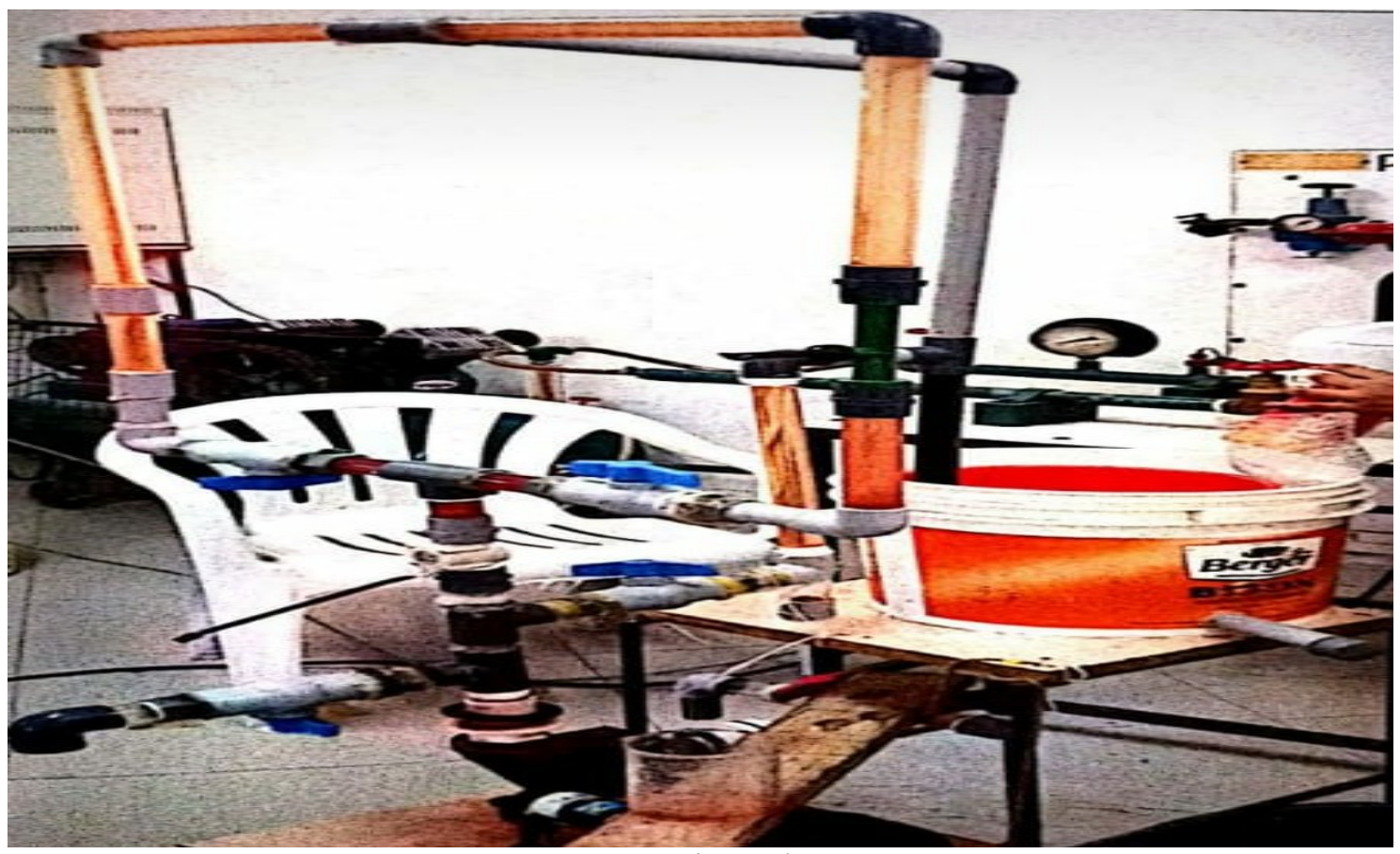

Fig 2:- Experimental set up.

\section{Experimental and analytical procedure:}

Decolorization of Congo red dye has been carried out using $\mathrm{HC}$ at various conditions with a fixed aqueous congo red dye solution of $10 \mathrm{~L}$ volume. All the experiments were performed for $120 \mathrm{~min}$, and samples were taken from the storage tank at a fixed interval of time for further analysis. During all the experiments, the temperature of the solution $\left(25 \pm 2^{\circ} \mathrm{C}\right)$ was kept constant and was maintained by circulating cooling water through the cooling jacket. The concentration of congo red dye was measured by UV/Vis-Spectrophotometer (Jasco800) at the wavelength $(\lambda \max )$ of $495 \mathrm{~nm}$. Firstly, the calibration chart was prepared for the known concentrations of congo red in the range of 10-150 ppm to calculate the concentration of unknown samples during experiments. A pH meter (systronics) was used to determine the $\mathrm{pH}$ of the solution throughout the experiments. In the present work, all experiments were repeated three times to evaluate the repeatability of the observed data.

\section{Results and discussion:- \\ Hydraulic Characteristics:}

In $\mathrm{HC}$, a dimensionless parameter known as cavitation number $(\mathrm{Cv})$ is used to characterize the condition of hydrodynamic cavitation inside a cavitating device. It is defined as the ratio of the pressure drop between the throat and extreme downstream section of the cavitating device to the kinetic head at the throat. Cavitation number is given by the following Eq

$$
C_{v}=\left(\frac{P_{2}-P_{v}}{\frac{1}{2} \rho v_{o}^{2}}\right)
$$

Where $\mathrm{P} 2$ is the fully recovered downstream pressure, $\mathrm{Pv}$ is the vapor pressure of the liquid, v0 is the velocity at the throat of the cavitating device, and $\rho$ is the density of the liquid. Two critical parameters, such as operating inlet pressure and cavitation number, affect the cavitational intensity at the downstream side of the cavitating device, i.e., the number of cavities being generated and their final collapse pressure. Thus, it is necessary to optimize the operating inlet pressure and cavitation number for all the cavitating devices.[11] The variation of cavitation number with operating inlet pressure for different cavitating devices is shown in Fig. 3. This figure reveals that the cavitation number decreases with an increase in operating inlet pressure for all the cavitating devices. As the inlet pressure 
increases, the volumetric flow rate through mainline and velocity at the throat increases, which in turn reduces the cavitation number. Hence, the overall cavitation number is affected by the inlet pressure and volumetric flow rate which also affects the number of cavitational events

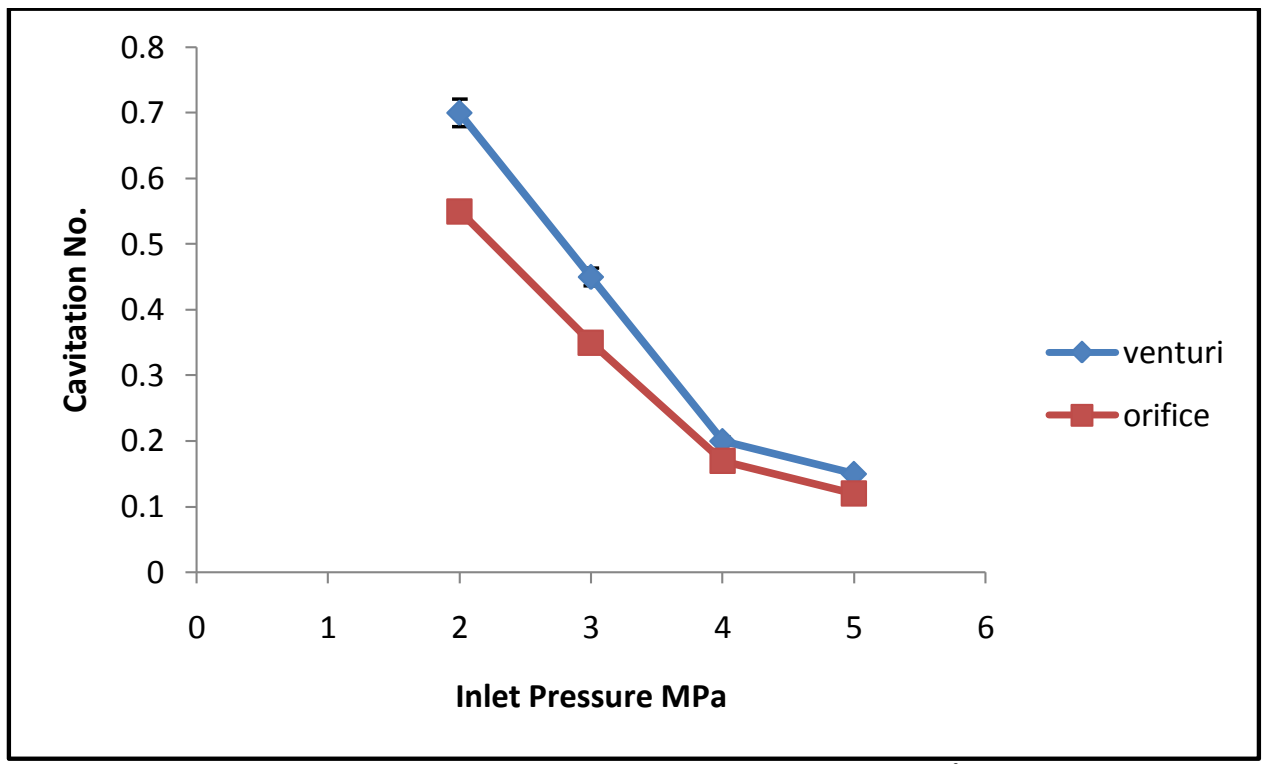

Fig 3:- Hydraulic characteristics (Reaction condition Volume 6 liter, temp $25{ }^{0} \mathrm{C}$, time $90 \mathrm{~min}$, conc. of Dye 30 ppm).

\section{Optimization of solution pH:}

The solution $\mathrm{pH}$ plays a crucial role in determining the productive decolorization efficiency of pollutants using HC.[12] The experiments related to optimization of solution $\mathrm{pH}$ were conducted at different solution $\mathrm{pH}$ ranging from 3 to 8 at an operating inlet pressure of $0.4 \mathrm{MPa}$ and dye initial concentration of 120ppm. In this case, orifice was used to generate the hydrodynamic cavitation. The obtained results are shown in Fig.4. The results depict that the extent of decolorization increases with a decrease in solution $\mathrm{pH}$. The maximum decolorization of $63 \%$ was obtained at a solution $\mathrm{pH}$ of 4 .using orifice and $73 \%$ using the venturi. The results clearly show that the extent of decolorization at acidic condition was greater as compared to that obtained at essential condition Higher decolorization rate at acidic condition can be attributed to the fact that the production of $\bullet \mathrm{OH}$ radicals in $\mathrm{HC}$ system are more favorable under acidic condition.

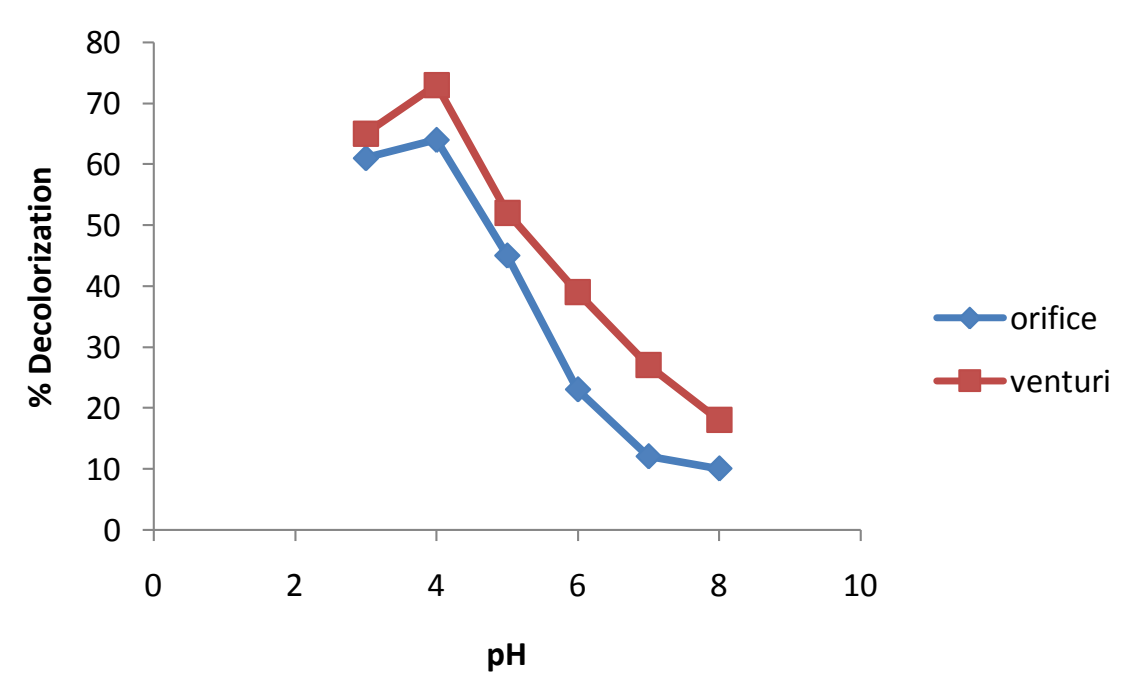

Fig.4:- Effect of pH (Reaction condition Volume 6 liter, temp $25{ }^{\circ} \mathrm{C}$, time $90 \mathrm{~min}$, conc. of Dye $30 \mathrm{ppm}$ ). 


\section{Effect of initial Congo red concentration:}

The Effect of initial concentration of congo red dye on the decolorization was investigated using orifice and venture as a cavitating device. Experiments were performed with different initial concentrations as 30, 60, 90 and $120 \mathrm{ppm}$ at an operating inlet pressure of $0.4 \mathrm{MPa}$ and solution $\mathrm{pH}$ of 4.0 . The extent of decolorization is inversely proportional to its initial concentration of Dye. It was observed that \% decolorization decreased from $64 \%$ to $19 \%$ with an increase in the initial concentration of congo red dye from 30 to $120 \mathrm{ppm}$, and $73 \%$ to $32 \%$ by using venturi. The obtained lower decolorization rate at higher concentration can be attributed to the fact that the total quantity of pollutant molecules increases with an increase in the initial concentration, whereas the total concentration of $\bullet \mathrm{OH}$ radicals remains constant in the system.[13]

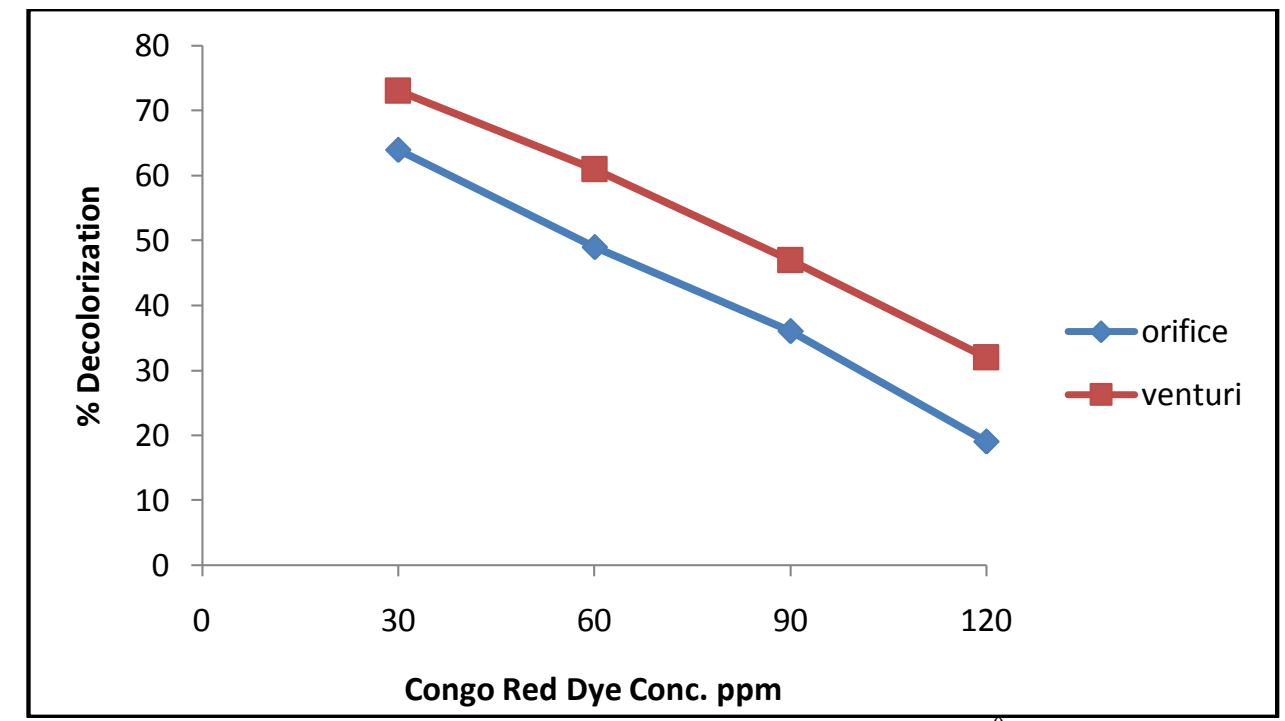

Fig 5:- Effect of dye conc. (Reaction condition Volume 6 liter, temp $25^{\circ} \mathrm{C}$, time $90 \mathrm{~min}, \mathrm{pH}$ 4).

\section{Effect of Flowrate:}

Inlet pressure is an important operating parameter of HC system.[14] In order to investigate the influence of inlet pressure on the decolorization rate of congo red dye. Experiments were conducted by varying flow rates from 0.2 to $0.6 \mathrm{~L} / \mathrm{s}$. The congo red dye concentration was kept constant at $30 \mathrm{mg} / \mathrm{L}$, and the $\mathrm{pH}$ value was fixed at 4.0 for a time period of $90 \mathrm{~min}$. Figure 6 showed the Effect of flow rate on the decolorization rate concerning time. The experimental results indicated that the rate of decolorization increased with an increase in flow rate ranging from 0.2 to $0.5 \mathrm{~L} / \mathrm{s}$, but beyond which no significant increase in the rate of decolorization

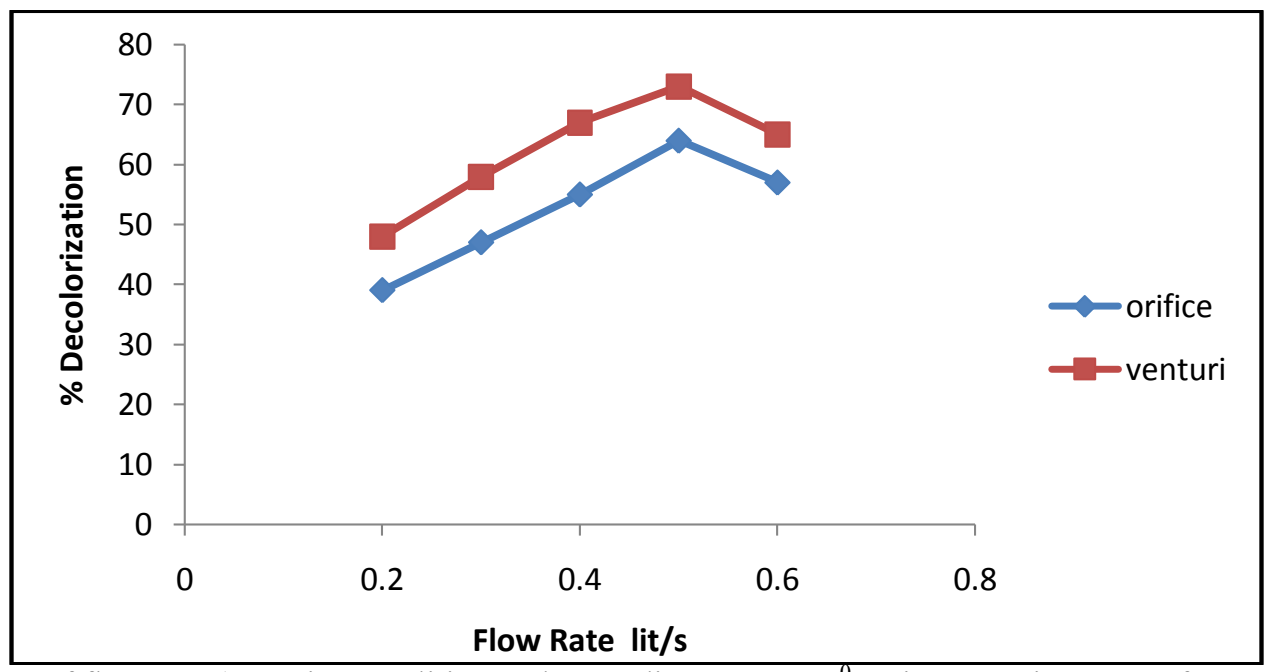

Fig 6:- Effect of flow rate (Reaction condition Volume 6 liter, temp $25^{\circ} \mathrm{C}$, time $90 \mathrm{~min}$, conc. of Dye $30 \mathrm{ppm}, \mathrm{pH}$ 4). 


\section{Effect of geometrical configurations (Comparison of venturi and orifice plates):}

It has been reported that venturi has advantages over an orifice plate due to their smooth convergent and divergent section, which prevents the early cavity collapse and enhances the cavity life. It is noted in the literature that venturi gave higher decolorization than orifice plates.[15] But while operating with the venturi, experimental set up repeatedly broke down due to high pressure developed. When venturi was compared with orifice plate having a circular hole. It was found that venturi gave higher decolorization than orifice plate, i.e., $73 \%$ in venturi and $64 \%$ in orifice) In case of orifice plates, the generated cavities in the downstream section do not reach their maximum size due to the sudden pressure drop, resulting into a lower cavitational activity as compared to venturi. Hence, organic pollutant molecules will get longer exposure time under cavitating condition in case of venturi than orifice plates. These results clearly show that venturi are better than orifice plates of the same flow area.

\section{Conclusions:-}

This work shows that the efficiency of hydrodynamic cavitation is strongly influenced by the geometrical parameters The maximum extent of decolorization of congo red dye was obtained using slit venturi at an optimum inlet pressure of $0.4 \mathrm{MPa}$ is $73 \%$ and using orificemeter is $64 \%$. It has been found that higher flow area is better for higher cavitational yield. Furthermore, it was observed that solution $\mathrm{pH}$ also affects the degradation efficiency of pollutants. These processes differ from the other treatment processes because wastewater compounds are degraded rather than concentrated or transferred into a different phase, and secondary waste materials are not generated.

\section{References:-}

1. S. V. Mohan, Y. V. Bhaskar, and J. Karthikeyan, "Biological decolourisation of simulated azo dye in aqueous phase by algae Spirogyra species,” Int. J. Environ. Pollut., vol. 21, no. 3, pp. 211-222, 2004.

2. V. A. Sakkas, M. A. Islam, C. Stalikas, and T. A. Albanis, "Photocatalytic degradation using design of experiments: A review and example of the Congo red degradation," J. Hazard. Mater., vol. 175, no. 1-3, pp. 33-44, 2010.

3. M. Kobya, O. T. Can, and M. Bayramoglu, "Treatment of textile wastewaters by electrocoagulation using iron and aluminum electrodes," J. Hazard. Mater., vol. 100, no. 1-3, pp. 163-178, 2003.

4. S. Wijetunga, X. F. Li, and C. Jian, "Effect of organic load on decolourization of textile wastewater containing acid dyes in upflow anaerobic sludge blanket reactor," J. Hazard. Mater., vol. 177, no. 1-3, pp. 792-798, 2010.

5. S. Erdemoğlu et al., "Photocatalytic degradation of Congo Red by hydrothermally synthesized nanocrystalline TiO2 and identification of degradation products by LC-MS," J. Hazard. Mater., vol. 155, no. 3, pp. 469-476, 2008.

6. Y. L. Pang and A. Z. Abdullah, "Current status of textile industry wastewater management and research progress in malaysia: A review," Clean - Soil, Air, Water, vol. 41, no. 8, pp. 751-764, 2013.

7. V. K. Saharan, M. P. Badve, and A. B. Pandit, "Degradation of Reactive Red 120 dye using hydrodynamic cavitation," Chem. Eng. J., vol. 178, pp. 100-107, 2011.

8. S. Rajoriya, S. Bargole, and V. K. Saharan, "Degradation of reactive blue 13 using hydrodynamic cavitation: Effect of geometrical parameters and different oxidizing additives," Ultrason. Sonochem., vol. 37, pp. 192-202, 2017.

9. M. Capocelli, M. Prisciandaro, A. Lancia, and D. Musmarra, "Hydrodynamic cavitation of p-nitrophenol: A theoretical and experimental insight," Chem. Eng. J., vol. 254, pp. 1-8, 2014.

10. T. Nikita Pareshbhai and H. Syed, "Dye Wastewater Treatment By Hydrodynamic Cavitation Process," no. 3, pp. 2395-4396, 2016.

11. S. Rajoriya, S. Bargole, S. George, and V. K. Saharan, "Treatment of textile dyeing industry effluent using hydrodynamic cavitation in combination with advanced oxidation reagents," J. Hazard. Mater., vol. 344, pp. 1109-1115, 2018.

12. R. K. Joshi and P. R. Gogate, "Degradation of dichlorvos using hydrodynamic cavitation based treatment strategies," Ultrason. Sonochem., vol. 19, no. 3, pp. 532-539, 2012.

13. L. P. Amin, P. R. Gogate, A. E. Burgess, and D. H. Bremner, "Optimization of a hydrodynamic cavitation reactor using salicylic acid dosimetry,” Chem. Eng. J., vol. 156, no. 1, pp. 165-169, 2010.

14. H. Kim, B. Koo, S. Lee, and J. Y. Yoon, "Experimental study of cavitation intensity using a novel hydrodynamic cavitation reactor,” J. Mech. Sci. Technol., vol. 33, no. 9, pp. 4303-4310, 2019.

15. C. D. Wu, Z. L. Zhang, Y. Wu, L. Wang, and L. J. Chen, "Effects of operating parameters and additives on degradation of phenol in water by the combination of $\mathrm{H} 2 \mathrm{O} 2$ and hydrodynamic cavitation," Desalin. Water Treat., vol. 53, no. 2, pp. 462-468, 2015. 